University of Wollongong

Research Online

1994

\title{
Influence of socioeconomic status, ethnicity and an educational brochure on compliance with a postal faecal occult blood test.
}

Julie M. King

University of New South Wales, jking@uow.edu.au

Gregory Fairbrother

University of New South Wales

Cristina J. Thompson

University of Wollongong, cthompso@uow.edu.au

David Morris

University of New South Wales, david.morris@unsw.edu.au

Follow this and additional works at: https://ro.uow.edu.au/ahsri

Research Online is the open access institutional repository for the University of Wollongong. For further information contact the UOW Library: research-pubs@uow.edu.au 


\title{
Influence of socioeconomic status, ethnicity and an educational brochure on compliance with a postal faecal occult blood test.
}

\author{
Abstract \\ The study aimed to determine if socioeconomic status and ethnicity affect compliance with postal faecal \\ occult blood test screening, and if compliance can be increased by adding an educational brochure. A \\ pilot intervention study was used in socioeconomically defined postcodes and defined census collection \\ districts of the Southern Sydney Area Health Service. The study population of men and women aged 45 to \\ 75 years was selected from general practice lists in the defined postcodes. Samples were comparable for \\ age, sex, and socioeconomic indices. Compliance, using a general practitioner letter alone, was: for the \\ Australian middle-socioeconomic status sample, 65.8 per cent ( 95 per cent confidence interval (Cl) 59.5 \\ to 72.1), the Australian low-socioeconomic status sample, 63.9 per cent (Cl 57.3 to 70.5 ), the Arabic \\ low-socioeconomic status sample, 33.3 per cent ( $\mathrm{Cl} 27.2$ to 39.4$)$. With the general practitioner letter plus \\ brochure, compliance was: Australian middle-socioeconomic status sample, 67.0 per cent $(\mathrm{Cl} 60.5$ to \\ 73.5), Australian low-socioeconomic status sample, 62.1 per cent ( $\mathrm{Cl} 55.3$ to 68.9$)$ and Arabic \\ low-socioeconomic status sample, 36.8 per cent ( $\mathrm{Cl} 30.6$ to 43.0). Compliance was higher in all \\ Australian samples than in Arabic samples. A brochure, designed to increase compliance with testing, \\ had no significant effect in Australian samples. Australian samples of different socioeconomic status \\ complied almost equally. Results suggest that advice from the local doctor is very effective in motivating \\ patients to screen with faecal occult blood testing. Low compliance to an invitation in Arabic and English \\ in an Arabic low-socioeconomic status population suggests that low literacy in one or both languages \\ may preclude compliance with screening in this group.
}

\section{Keywords}

influence, postal, compliance, brochure, educational, ethnicity, status, test., blood, occult, socioeconomic, faecal

\section{Publication Details}

J. King, G. Fairbrother, C. Thompson \& D. L. Morris, "Influence of socioeconomic status, ethnicity and an educational brochure on compliance with a postal faecal occult blood test.", Australian Journal of Public Health 181 (1994) 87-92. 


\title{
Influence of socioeconomic status, ethnicity and an educational brochure on compliance with a postal faecal occult blood test
}

\author{
Julie King \\ Department of Surgery, University of New South Wales, Sydney \\ Gregory Fairbrother \\ Department of Surgery, University of New South Wales, Sydney \\ Cristina Thompson \\ Health Promotion Unit, Southern Sydney Area Health Service \\ David L. Morris \\ Department of Surgery, University of New South Wales, Sydney
}

\begin{abstract}
The study aimed to determine if socioeconomic status and ethnicity affect compliance with postal faecal occuit blood test screening, and if compliance can be increased by adding an educational brochure. A pilot intervention study was used in socioeconomically defined postcodes and defined census collection districts of the Southern Sydney Area Health Service. The study population of men and women aged 45 to 75 years was selected from general practice lists in the defined postcodes. Samples were comparable for age, sex, and socioeconomic indices. Compliance, using a general practitioner letter alone, was: for the Australian middle-socioeconomic status sample, 65.8 per cent (95 per cent confidence interval (CI) 59.5 to 72.1), the Australian low-socioeconomic status sample, 63.9 per cent (CI 57.3 to 70.5), the Arabic low-socioeconomic status sample, 33.3 per cent (CI 27.2 to 39.4 ). With the general practitioner letter plus brochure, compliance was: Australian middle-socioeconomic status sample, 67.0 per cent (CI 60.5 to 73.5), Australian low-socioeconomic status sample, 62.1 per cent (CI 55.3 to 68.9) and Arabic low-socioeconomic status sample, 36.8 per cent (CI 30.6 to 43.0). Compliance was higher in all Aust ralian samples than in Arabic samples. A brochure, designed to increase compliance with testing, had no significant effect in Australian samples. Australian samples of different socioeconomic status complied almost equally. Results suggest that advice from the local doctor is very effective in motivating patients to screen with faecal occult blood testing. Low compliance to an invitation in Arabic and English in an Arabic low-socioeconomic status population suggests that low literacy in one or both languages may preclude compliance with screening in this group. (Aust J Public Health 1994; 18: 87-92)
\end{abstract}

$\mathrm{C}$ olorectal cancer is the most common cause of cancer death among nonsmokers in Australia.' Incidence is very closely age-related and the aging of the Australian population has resulted in an increase in the number of new cases of colorectal cancer from 6926 in 1982 to an estimated 9300 in 1991." The ongoing randomised trials have already shown that cancers detected by faecal occult blood test screening include more early stage tumours. ${ }^{3-t i}$ Compliance with the screening offer is crucial because low compliance rates limit the impact of screening on colorectal mortality and are incompatible with an efficient and cost-effective program.?

We had conducted prior work in the Southern Sydney Area Health Service to assess the best method of screening for colorectal cancer using a postal faecal occult blood test. The most successful approach achieved a compliance rate of 55 per cent. ${ }^{8}$ We used a personalised general practitioner invitation, two test kits, a test instruction sheet, a stamped self-addressed envelope and two reminder letters at monthly intervals. $^{\text {. }}$

Correspondence to Professor D.L. Morris, Department of Surgery, St George Hospital, Belgrave Street, Kogarah, NSW 2217. Fax (02) 3503997
It is accepted that general practitioner patient lists are both representative and relatively current, with over 80 per cent of Australians visiting general practitioners in 1989-1990. ${ }^{4.11}$ General practitioners are ideally placed to impart information on prevention and early detection of disease, being regarded by their patients as a primary source of health information." Patients are more likely to modify their health risk behaviours if so advised by their doctor rather than a centralised health agency. ${ }^{12}$

Australia is not a classless society, and although there is less variation in morbidity according to class than in other countries, low socioeconomic status is associated with health risks, poorer health knowledge and attitudes. Inequality is primarily based on wealth, occupation and ethnic origin. Public housing, which is an indicator of disadvantage, is concentrated in less affluent suburbs. ${ }^{13-16}$

Our prior study indicated that including a government brochure on colorectal cancer with the postal invitation and a faecal occult blood test kit did not increase compliance. Structured interview results of those who did not comply with screening suggested that the addition of a simple specific brochure on faecal occult blood testing might enhance compliance with a postal invitation from a general practitioner. ${ }^{8}$ 
Our present study aimed to investigate the effect of socioeconomic status and ethnicity on compliance with faecal occult blood test screening.

\section{Method}

This study had three components:

- the effect of socioeconomic status on compliance

- the effect of an educational brochure on compliance

- the effect of ethnicity on compliance

\section{Socioeconomic disadvantage}

Before the study, we consulted the Australian Bureau of Statistics (ABS) regarding the demography of the area and sample derivation. ${ }^{17}$ We selected the suburbs of Ramsgate/Sans Souci and Riverwood to reflect mainly Australian-born middle- and low-socioeconomic status populations in the area. Ramsgate and Sans Souci are mid-range socioeconomic status suburbs, and Riverwood has a large low-socioeconomic status population, with the highest concentration of government subsidised housing in the area. We used the ABS urban Index of Relative Socioeconomic Disadvantage and Index of Education/ Occupation derived from the 1986 Census of Population and Housing as indicators of socioeconomic status. The indices reflect the socioeconomic wellbeing of an area, rather than of individuals. The collection district is the smallest definable area, with a range of 51 to 338 dwellings in this area.

To select samples with a majority of Australianborn persons of middle- and low-socioeconomic status, we enlisted the support of general practioners from four practices, selected at random from 23 in the chosen postcodes of Ramsgate/Sans Souci and Riverwood. We selected the middle-socioeconomic status sample from Ramsgate/Sans Souci by taking only those patients who resided in collection districts which had index values in the middle range of all values for the postcodes. Mean index values for Ramsgate/Sans Souci lie in the 50 to 75 per cent quartile range of values for New South Wales. ${ }^{17}$ We selected a low-socioeconomic status sample from Riverwood by taking only patients who resided in collection districts which had index values in the middle to low range of all values for the postcode. Mean index values for Riverwood lie in the lowest quartile range of values for New South Wales. ${ }^{17}$ We needed an increase of 15 per cent in compliance from a baseline of 50 per cent to justify adding a brochure. Power calculations suggested that each sample should have 182 subjects to have an 80 per cent chance of detecting a 15 per cent increase $(P<0.05)$.

\section{Educational brochure}

We worked with a graphic artist to design a lowliteracy brochure aimed to motivate 45- to 75-yearold men and women to comply with the screening. The brochure was written in simple language with brightly coloured illustrations and was pretested in that age group. The educational message was that men and women were both susceptible to colorectal cancer and that for people over forty, risk increased with age. The brochure emphasised that the disease was curable with early detection. More than 50 per cent of the brochure content was a graphic explanation of the faecal occult blood test procedure. The brochure was translated into Arabic and pretested by Arabic speakers.

\section{Immigrant ethnic group}

The effect of ethnicity on likely compliance with faecal blood testing for colorectal cancer in Australia is largely unknown. We selected the third population sample, from the Arncliffe postcode, an area of relatively low socioeconomic status with a large Arabicspeaking population. The mean index values for Arncliffe lie in the lowest quartile range of values for New South Wales. Three Arabic-speaking solo general practitioners (of six eligible Arabic practices in the area) agreed to participate. It was verified by the doctor that all patients were of Arabic ethnicity and not Australian-born. The Arabic population of the area has a young age distribution, with 83.4 per cent of the Arabic-speaking population being under $\mathbf{4 5}$ years. ${ }^{18}$ Because of the small minority population, it was necessary to use all Arabic persons in the age range who resided within the Arncliffe and immediate surrounding postcodes, rather than in collection districts.

\section{Study details}

Each general practitioner was informed of the study aims and protocol. Data were collected on 2769 patients, with the criteria of age range 45 to 75 years, resident of the relevant postcode and having current patient status (consultation within the previous two years). A database was created for each practice, with each patient's name, address, sex, date of birth and whether the spouse was also offered screening. Patient data were collected by two research assistants, practices were cross-checked for patient duplication and patient data were combined into three sample populations. A total of 111 people (4.2 per cent) were excluded by their doctors because of concurrent colorectal disease, other serious pathology or infirmity. The final sample size was 1281 . The three samples were defined as Ramsgate/Sans Souci: mainly Aust ralian-born, middle socioeconomic status $(n=422)$, Riverwood: Australian, low socioeconomic status $(n=400)$ and Arncliffe: Arabic, low socioeconomic status $(n=459)$ (Table 1$)$. All samples were comparable for sex, but the young age distribution of the immigrant minority population is reflected in the Arncliffe sample (Table 2).

Clusters of patients of each general practitioner were randomly allocated to either of the screening invitation methods within each of the three samples. The personalised invitation to complete the faecal occult blood test, signed by the doctor, provided information about colorectal cancer screening. The test instruction sheet was written in simple language and enclosed with a prepaid addressed envelope. Arabic samples were further divided. One group received either an Arabic language letter and test instruction sheet or an Arabic language letter and brochure. The other Arabic group received an English language letter and an Arabic test instruction sheet or an English language letter and Arabic brochure. The sample was divided after data collection because one Arabic doctor specifically requested that 
Table 1: Derivation of samples from general practitioner patient lists

\begin{tabular}{|c|c|c|c|c|c|c|}
\hline \multirow[t]{2}{*}{$\begin{array}{l}\text { Postcode and } \\
\text { collection district }\end{array}$} & \multirow[t]{2}{*}{$\begin{array}{c}\text { Area socioeconomic } \\
\text { status }\end{array}$} & \multirow{2}{*}{$\begin{array}{c}\text { Eligible potients } \\
45 \text { to } 75 \text { years } \\
n\end{array}$} & \multicolumn{2}{|c|}{$\begin{array}{c}\text { Patients excluded by } \\
\text { own GPs }\end{array}$} & \multirow{2}{*}{$\begin{array}{c}\text { Patients excluded by socio- } \\
\text { economic indices or postcode } \\
n\end{array}$} & \multirow{2}{*}{$\begin{array}{c}\text { Final } \\
\text { somple } \\
n\end{array}$} \\
\hline & & & $n$ & $\%$ & & \\
\hline Ramsgate/Sans Souci & $\begin{array}{l}\text { Australian-born } \\
\text { middle status }\end{array}$ & 1226 & 64 & 5.2 & 740 & $422^{\circ}$ \\
\hline Riverwood & $\begin{array}{l}\text { Australian-born } \\
\text { low status }\end{array}$ & 919 & 26 & 2.8 & 493 & $400^{\circ}$ \\
\hline Arncliffe & $\begin{array}{l}\text { Arabic-born } \\
\text { low status }\end{array}$ & 624 & 21 & 3.4 & 144 & $459^{b}$ \\
\hline Total & & 2769 & 111 & 4.0 & 1377 & 1281 \\
\hline
\end{tabular}

Notes: (a) Final sample selected on the basis of collection district index value (b) Final sample selected on the basis of postcode.

Table 2: Age and sex distributions (\%) of samples ${ }^{\circ}$

\begin{tabular}{|c|c|c|c|c|c|c|}
\hline \multirow[b]{2}{*}{$\begin{array}{l}\text { Age } \\
45 \text { to } 54 \\
55 \text { to } 64 \\
65 \text { to } 74\end{array}$} & \multicolumn{2}{|c|}{\begin{tabular}{cc}
\multicolumn{2}{c}{ Ramsgate/Sans Souci } \\
Australian middle socioeconomic status \\
Letter & Letter + brochure \\
$n=219$ & $n=203$ \\
\end{tabular}} & \multicolumn{2}{|c|}{$\begin{array}{c}\text { Riverwood } \\
\text { Australian low socioeconomic status } \\
\text { Letter } \quad \text { Letter }+ \text { brochure } \\
n=205 \quad n=195\end{array}$} & \multicolumn{2}{|c|}{$\begin{array}{c}\text { Arncliffe } \\
\text { Arabic low socioeconomic status } \\
\text { Letter } \quad \text { Letter }+ \text { brochure } \\
n=231 \quad n=228\end{array}$} \\
\hline & $\begin{array}{l}25.6 \\
26.9 \\
47.5\end{array}$ & $\begin{array}{l}28.6 \\
31.5 \\
39.9\end{array}$ & $\begin{array}{l}25.4 \\
25.9 \\
49.3\end{array}$ & $\begin{array}{l}24.6 \\
30.8 \\
44.6\end{array}$ & $\begin{array}{l}52.8 \\
29.9 \\
17.3\end{array}$ & $\begin{array}{l}54.8 \\
27.6 \\
17.5\end{array}$ \\
\hline $\begin{array}{l}\text { Sex } \\
\text { Female }\end{array}$ & 58.0 & 60.6 & 62.4 & 62.1 & 46.3 & 47.4 \\
\hline
\end{tabular}

Note: (a) All postal invitations included two faecal occult blood test kits, test instructions and prepaid postage.

the entire screening offer be delivered to his patients in Arabic. The other Arabic doctors preferred a combined English/Arabic-language strategy. We considered this protocol change useful as it allowed for investigation of compliance according to the language of delivery.

Two reminder letters were sent at one-month intervals. The project was commenced in July 1991 and completed in April 1992. The most widely used guaiac faecal occult blood test, Hemoccult Sensa (Smith Kline Diagnostics, Sunnyvale, California) was used without dietary restriction. Returned kits were developed on receipt without rehydration and the results of any positive tests communicated immediately to the general practitioner. All Hemoccult Sensa were tested by either researcher and each positive result was assessed by both researchers.

Chi-square analysis was used to determine if there were significant differences in compliance rates between the six samples and the variables of age, sex and partner status.

\section{Results}

A total of 693 of 1235 (56.1 per cent) subjects in combined samples completed the test. Compliance was greater among females in both the Australian middle- and low-socioeconomic status samples. Interestingly, the differences were significant in the 'GP Letter' samples, but not in the 'GP Letter + Brochure' samples $(P<0.05)$. Compliance was greater among the older subjects ( 65 to 74 years) in all samples, both Australian and Arabic (Figure 1). Subjects in the youngest age range complied least, and this was significant in the 'GP Letter' sample of middle socioeconomic status $(P<0.001)$ and 'GP Letter + Brochure' samples of middle and low socioeconomic status $(P<0.01)$.
The educational brochure did not improve compliance in any of the samples. Socioeconomic status had no significant effect on compliance. There was a large difference in compliance between the four Australian and the two Arabic samples $(P<0.001)$ and a significant difference between Australian and Arabic low socioeconomic groups $(P<0.001)$. The number 'returned to sender' was quite low at 3.6 per cent in the four Australian samples but higher at 5.7 per cent in the two Arabic samples (Table 3). Of the 161 returned kits in the Arabic samples, 25 (15.5 per cent) were incorrectly completed. This was a high rate compared with 20 ( 3.8 per cent) of 532 returned in the Australian samples $(P<0.001)$.

The effect of reminder letters was substantial in all samples (Figure 2). The first reminder achieved a mean compliance increase of 11.7 per cent in Australian middle-socioeconomic status samples, 12.5 per cent in Australian low-socioeconomic status

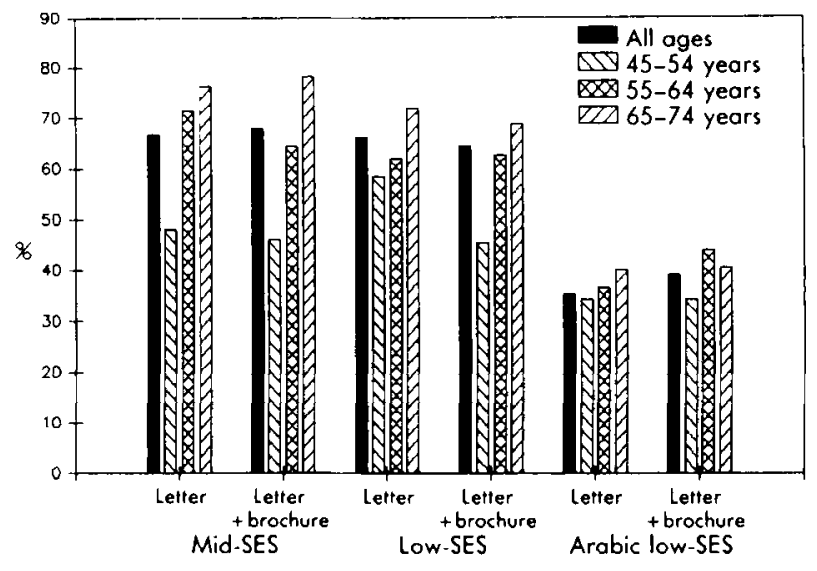

Figure 1: Compliance $(\%)$ with faecal occult blood test screening 
Table 3: Compliance breakdown of samples

\begin{tabular}{|c|c|c|c|c|c|c|c|c|}
\hline Sample category & $\begin{array}{c}\text { Invitations } \\
\text { sent } \\
n\end{array}$ & $\underset{n}{\text { Compliers }}$ & $\begin{array}{c}\text { Actual } \\
\text { compliance } \\
\% \\
\end{array}$ & $95 \% \mathrm{Cl}^{\circ}$ & $\begin{array}{c}\text { Returned } \\
\text { to sender } \\
n\end{array}$ & $\begin{array}{c}\text { Invitations } \\
\text { remaining } \\
n\end{array}$ & $\begin{array}{c}\text { Amended } \\
\text { compliance } \\
\%\end{array}$ & $95 \% \mathrm{Cl}$ \\
\hline $\begin{array}{l}\text { Ramsgate/Sans Souci, letter } \\
\text { Ramsgate/Sans Souci, }\end{array}$ & 219 & 144 & 65.8 & 59.5 to 72.1 & 3 & 216 & 66.7 & 60.4 to 73.0 \\
\hline $\begin{array}{l}\quad \text { lefter + brochure } \\
\text { Riverwood, letter } \\
\text { Riverwood, letter + brochure } \\
\text { Arncliffe, lefter } \\
\text { Arncliffe, letter + brochure } \\
\text { Total }\end{array}$ & $\begin{array}{l}203 \\
205 \\
195 \\
231 \\
228 \\
1281 \\
\end{array}$ & $\begin{array}{r}136 \\
131 \\
121 \\
77 \\
84 \\
693 \\
\end{array}$ & $\begin{array}{l}67.0 \\
63.9 \\
62.1 \\
33.3 \\
36.8\end{array}$ & $\begin{array}{l}60.5 \text { to } 73.5 \\
57.3 \text { to } 70.5 \\
55.3 \text { to } 68.9 \\
27.2 \text { to } 39.4 \\
30.6 \text { to } 43.0\end{array}$ & $\begin{array}{r}3 \\
7 \\
7 \\
13 \\
13 \\
46 \\
\end{array}$ & $\begin{array}{r}200 \\
198 \\
188 \\
218 \\
215 \\
1235 \\
\end{array}$ & $\begin{array}{l}68.0 \\
66.2 \\
64.4 \\
35.3 \\
39.1\end{array}$ & $\begin{array}{l}61.5 \text { to } 72.8 \\
59.6 \text { to } 72.8 \\
57.5 \text { to } 71.2 \\
28.0 \text { to } 41.7 \\
32.6 \text { to } 45.6\end{array}$ \\
\hline
\end{tabular}

Notes: (a) $\mathrm{Cl}=$ confidence interval. (b) Amended compliance is compliance rate when letters returned to sender are excluded.

samples and 9.7 per cent in Arabic lowsocioeconomic status samples. The second reminder achieved a mean compliance increase of 10.6 per cent in Australian middle-socioeconomic status samples and 6.8 per cent in Australian lowsocioeconomic status samples and 3.1 per cent in Arabic low-socioeconomic status samples.

The all-Arabic language group $(n=142)$ achieved a compliance rate of 47.8 per cent, compared with the English/Arabic language group's $(n=317) \mathrm{com}$ pliance rate of 27.7 per cent. This difference was significant $(P<0.001)$.

\section{Test results}

Overall, 693 Hemoccult Sensa tests were returned, but lack of identification or excessive faecal matter precluded testing of 7.9 per cent of the returned kits. Seventeen (1.3 per cent) of the completed tests were positive. Diagnostic investigation found six people (35.3 per cent) with neoplastic disease, four with nonneoplastic colorectal conditions and four with no abnormality. Of patients with neoplasia, there was one Dukes' B and one Dukes' $C$ cancer and one patient with malignant change of moderately differentiated carcinoma. Also, three patients had large polyps, two of $2 \mathrm{~cm}$ and one of $1 \mathrm{~cm}$.

\section{Discussion}

Good compliance rates were achieved in Australian samples using a postal invitation from a general practitioner (62 to 67 per cent) and compliance improved upon previously achieved Australian rates. ${ }^{19.8}$ There was no difference in compliance on the basis of socio-

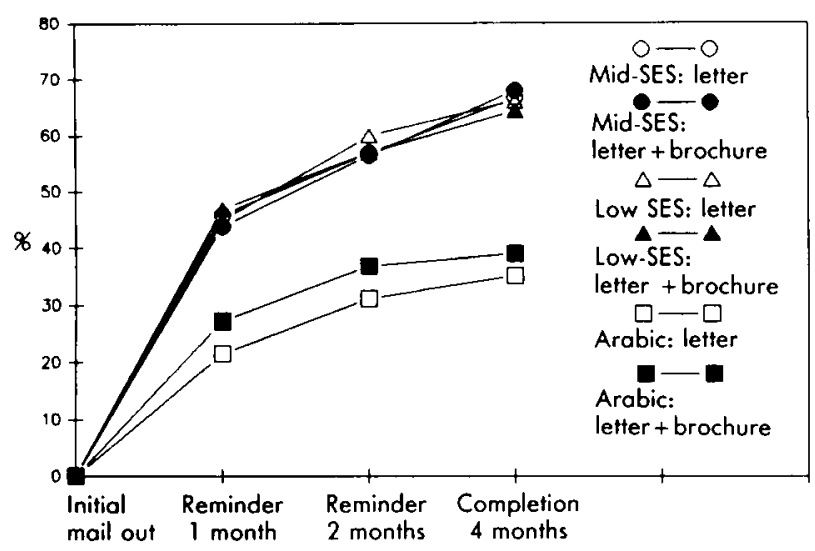

Figure 2: Compliance $(\%)$ with faecal occult blood test screening in each sample economic status in Australian-born samples, nor was there any advantage in adding a brochure. It was more cost-effective to use a letter from the general practitioner alone. It is very encouraging that sample groups of different socioeconomic status complied almost equally, when previous research in Australia and overseas has indicated that people in lower socioeconomic groups comply less well. ${ }^{7.20}$

Nichols et al. showed that offering educational material did not increase compliance with faecal occult blood testing in English population samples, and the results of our study concur with this finding. ${ }^{21}$ The simple educational brochure had no additional effect on compliance in either middle- or low-socioeconomic Australian samples. In fact, the low-socioeconomic status sample achieved high compliance of 63.9 per cent with the letter from the general practitioner, compared with 62.1 per cent achieved with the letter and brochure. We can only presume that both middle- and low-socioeconomic status Australian population groups are more likely to comply with postal screening when the invitation is sanctioned by their local doctor and when they consider themselves current patients.

Females achieved a higher compliance rate in all Australian samples. This was statistically significant in the Australian middle- and low-status 'GP Letter' samples $(P<0.05)$. Age also affected compliance. Subjects in the age group 65 to 74 years for all four Australian samples complied significantly better than younger patients (Figure 1).

International investigations of the relationship between compliance with screening and socioeconomic status have suggested that the latter has a variable effect on compliance behaviour. Some studies have demonstrated an increase in compliance in subjects of higher status, with others suggesting an opposite, or no effect. ${ }^{19-2 y}$

Compliance rates were disappointingly low in Arabic samples. Whilst there is good evidence that Southern European and Middle Eastern people have a much lower incidence of colon cancer than the Australian-born, immigrants can expect their risk to increase to that of the Australian-born rate after 15 to 20 years. ${ }^{23.24}$ Although we had sought the views of Arabic community organisations concerning the screening process prior to implementation of the study, it seems likely that unrecognised cultural attitudes may affect screening behaviour.

Ethnicity is widely recognised as a factor which divides people into advantaged and disadvantaged groups in health matters. ${ }^{25}$ In Australia, Middle East- 
ern and Southern European immigrants have the weakest English skills and least education. ${ }^{26}$ The urban population of the Southern Sydney Area Health Service is diverse in terms of both socioeconomic status and ethnicity and contains over 27 per cent of all Arabic speakers in New South Wales. ${ }^{\text {14 }}$ We presumed that the majority of those of Arabic speaking background were relatively recent arrivals, with a limited understanding and practice of preventive health behaviour." Health services specific to particular ethnic groups were introduced nationally in 1970, and bilingual health education programs were introduced in the $1980 \mathrm{~s}$, but knowledge of some aspects of migrant health remains as scant as in 1976. ${ }^{2 x}$

There was a highly significant difference in compliance between the Australian and Arabic samples Both the Arncliffe and Riverwood low-status samples were derived from postcodes in the lowest quartile of New South Wales for both socioeconomic indices used.

On this basis we could have expected similar compliance rates, if all other variables of age, sex and ethnicity were the same. It is likely that ethnicity is the variable which has caused the low compliance.

In the Arabic language group which was offered the English/Arabic screening invitation, compliance was lower compared with the all-Arabic language group $(P<0.001)$. This group was, however, derived from one practitioner who may have had a closer relationship with his patients.

We have demonstrated that people of Arabic background in Australia are less likely than Australianborn groups to participate in faecal occult blood screening, even when the invitation is from their own general practitioners. Ethnicity may be an important barrier to achieving optimal compliance with any population screening program. Perceived costs of participation were not likely to have been a major factor precluding patient compliance with the screening offer as Australia has a well-established national health scheme.

We did not provide for a quantitative record of patient queries to general practitioners and secretarial staff, but the Arabic-speaking practices recorded many patient queries as to why a specific individual had been chosen to receive a screening offer, and as to how the doctor knew that he or she already had colorectal cancer! The number of tests incorrectly collected by the Arabic subjects was inordinately high compared with the Australian samples. We had taken precautions to number and record all Arabic letters and testing kits. We were thereby able to determine that returned tests were nominally from the addressee, even though they were often returned unlabelled. We had presumed that the Arabic lowsocioeconomic status sample would have poor English literacy overall, but that this inhibition about screening would be remedied by an Arabic language invitation. A compliance rate of 47 per cent was achieved using the all-Arabic language screening offer, but this was an expensive process which yielded limited results.

High rates of incorrectly completed and returned kits suggest that low levels of literacy in both English and Arabic may have contributed to the low participation rate among Arabic patients. The Arabic- speaking community has the largest proportion of uneducated people in the Southern Sydney population, with one third of its adult members never having attended school. ${ }^{18}$ Eighty-five percent of the Arabic birthplace group are not recent arrivals, having been in Australia more than five years, and yet the issue of language difference remains acute, with 21.8 per cent having little or no English competence. ${ }^{18,29}$ It should be recognised that the effect of illiteracy in the language of origin or adoption must be taken into account when planning any population screening program.

\section{Acknowledgments}

We are grateful to the following doctors who actively participated in our screening programs: E. Amin, A. Bemand, N. Burton, A. Chan, J. Davis, G.W. Dunlop, H.E. Frankland, M. Gad, A. Gilroy, M. Gleeson, R. Hardie, B. Harrison, M. Hourani, M. Jacobi, S. Miles, A. Ruello.

Funding for this project was provided by the Southern Sydney Area Health Service.

\section{References}

1. Giles GG, Armstrong BK. Smith I.R. Cancer in Australia 1982. Publication no. 1. Canberra: Australian Institute of Health, 1987.

2. McCreadie $M$, Coates $M$. Cancer incidence by region. NSW and ACT 1979-1983. Sydney: NSW Cancer Council, I991.

3. Hardcastle JD, Chamberlain J. Sheffieid J, Balfour J. Random controlled trial of faecal occult blood screening for colorectal cancer: results for 107349 subjects. Lancet 1989 ; 1: $1160-4$.

4. Kronborg O, Fenger G, Sondergaard K, Pedersen K M, Olsen J. Initial mass screening for colorectal cancer with faecal occult blood test, a prospective randomised study at Funen, Denmark. Scand / Gastroenterol 1978; 22: 677-86.

5. Kewenter J, Bjork S, Haglind E, Smith L, et al. Screening and rescreening for colorectal cancer: a controlled trial of faecal occult blood test in 27000 subjects. Cancer 1988; 62: 645-51.

6. Faivre J, Arveux P, Milan C, Durand G, et al. Participation in mass screening for colorectal cancer: results of screening and rescreening from the Burgundy study. Eur / Cancer Prevent 1991; 1: 49-55

7. Snyder Halper M, Winawer S, Brody RS, Andrewa M, et al Issues of patient compliance. In: Winawer S, Schottenfeld D, Sherlock P, editors. Colorectal cancer: preventiom, epidemiology and screening. New York: Raven Press, 1980: 299-311.

8. King J, Fairbrother G, Thompson C, Morris DI. Population screening for colorectal cancer: achieving optimal compliance with postal faecal occult blood test. Aust NZ I Surg 1992; 62: 37-42.

9. Sanson-Fisher RW, Webb GR, Reid AlA. The role of the medical practitioner as an agent for disease prevention. In: Looking forward to better health. Canberra: Australian Government Publishing Service, 1986

10. Deeble J. Medical services through Medicare. National Health Strategy background paper no. 2. Canberra: Australian Govermmenı Publishing Service, 1991.

11. Trumble: S. The GP as a teacher. Med J Aust 1991; 155: 322-4.

12. Silagy C, Sommer S, Piterman 1. Preventive care in general practice. Med J Aust 1992; 156: 404-8.

13. Westem JS. Social inequality in Australian society. Sydney: Macmillan, 1983.

14. Siskind V, Copeman R, Najman JM. Socio-economic status and mortality: a Brisbane area analysis. Community Health Stud 1987; 11: 65-72.

15. Najman JM, Brown N, Bain C, Gibbings M, et al. Patterns of morbidity, health care utilisation and socio-economic status in Brisbane. Aust NZ / Sociology 1979; 15: 55-63. 
16. Horvath RJ, Harrison G, Dowling R.M. A social atlas of Sydney. Sydney: Sydney University Press, 1990: 86.

17. Mcl.ennan W. Australian Bureau of Statistics index data sets: ABS Socio ecomomic indexes for areas. Cat. no. 1356.0. and CEIFA database profile. Canberra: ABS, 1990.

18. Choucair S. A profile of language and birthplace groups in the Southern Sydney Area Health Service. State Health Publication (SSAHS) 90-81. Sydney: NSW Department of Health, 1991. ISBN 730534405

19. Macrae FA, St John DJB, Arunasalam A, Sharpe K, Garner JF and the Ballarat General Practitioner Research Group. Factors affecting compliance in colorectal cancer screening: results of a study performed in Ballarat. Med J Aust 1986 144: $621-3$.

20. Farrands PA, Hardcastle JD, Chamberlain J, Moss S. Factors affecting compliance with screening for colorectal cancer. Community Med 1984; 6: 12-9.

21. Nichols S, Koch E, Lallemand RC, Heald RI, et al. Randomised trial of compliance with screening for colorectal cancer. $B M J$ 1986; 293: 107-10.

22. Dent $O$, Goulston $K$, Public knowledge and attitudes on colorectal carcinoma and screening in a New South Wales rural town. Community Health Stud 1978; 11: 20-6.
23. Mc Michael AJ, Giles G. Cancer in migrants to Australia: extending the descriptive epidemiological data. Cancer Res $1988 ; 48: 751-6$.

24. McMichael AJ, McCall MG, Hartshorne JM, Woodings TL. Patterns of gastro-intestinal cancer in European migrants to Austraila: the role of dietary change. Int J Cancer 1980; 25 : $431-7$.

25. Bates E, Linder-Pelz S. Health care issues. Studies in society. 2nd ed. Sydney: Allen and Unwin, 1990.

26. Australian immigration: consolidated statistics 1989-90. No. 16. Canberra: Australian Bureau of Immigration Research, 1991.

27. Chapman M. The health promotion needs of the Arabic speaking and Macedonian communities of the St George district: a community research project, 1989. Sydney: Southern Sydney Area Health Service, 1989

28. Martin JI. The economic condition of migrants in welfore and migrants. Report no. 1. Research Repori for the Commission of Enquiry into Poverty, Canberra: Australian Government Publishing Service, 1976.

29. Australian Bureau of Immigration Research: Statistics Section. Community profiles: Lebanon bom. Canberra: Australian Government Publishing Service, 1990.

\title{
Mortality and coronary heart disease in diabetes mellitus
}

\author{
Vincent J. McCann \\ Diabetic Clinic, Royal Perth Hospital \\ Matthew W. Knuiman \\ Department of Public Health, University of Western Australia, Perth \\ Kim G. Stanton \\ Diabetic Clinic, Royal Perth Hospital \\ Michael G. Winter \\ Department of Public Health, University of Western Australia, Perth
}

\begin{abstract}
A clinic-based study of 1063 patients with Type 2 diabetes recruited from 1973 to 1982 identified 533 deaths (attributed to coronary heart disease in 268 cases) by 31 December 1989 . When compared to the general population of Australia the overall standardised mortality ratio was 1.42 (95 per cent confidence interval (CI) 1.26 to 1.58) for females and 1.19 (CI 1.03 to 1.35 ) for males. Cox regression analysis showed that having coronary heart disease or absence of foot pulses at the time of entrance to the study were the major independent risk factors for overall mortality after adjustment for initial age. Elevated cholesterol and blood pressure were found to be major independent risk factors for death from coronary heart disease. (Aust J Public Health 1994; 18: 92-5)
\end{abstract}

$\mathrm{P}$ atients with diabetes have an increased mortality rate, which has been reported in some studies to be as much as twice that of the nondiabetic population. ${ }^{1}$ This increased mortality can be attributed to vascular disease, with heart disease accounting for death in about 40 to 50 per cent and cerebrovascular disease in about 15 to 20 per cent of patients with Type 2 diabetes. ${ }^{1-3}$

Diabetes probably constitutes an independent additional risk factor for vascular disease and magnifies the effect of conventional risk factors like hyperlipidaemia, hypertension and smoking. ${ }^{4.5}$ Proteinuria may reflect this additional risk, being a predictor for vascular disease as well as an indication of diabetic nephropathy. ${ }^{6}$

Correspondence to Dr Vincent McCann, Diabetic Clinic, Royal Perth Hospital, GPO Box X2213, Perth, WA 6001. Fax (09) 224 3511.
This study examines all-cause mortality and deaths from coronary heart disease and their relationships to known cardiovascular risk factors in patients with Type 2 diabetes. The aims of the analysis were first, to estimate the survival rate of this cohort of diabetic patients and to make comparisons with the general population, and secondly, to examine the prognostic significance of the variables measured at the time of the initial survey on time to death from any cause and death from coronary heart disease.

\section{Materials and methods}

Patients and measurements

Starting in 1973, diabetic patients who attended the Royal Perth Hospital Diabetic Clinic were invited to participate in a survey which included a questionnaire and physical examination every two years. The patients selected for survey were younger and 